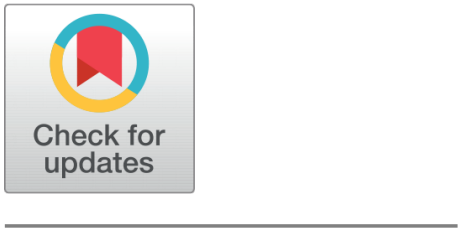

OPEN ACCESS

Received: 03-08-2020

Accepted: 17-08-2020

Published: 15-09-2020

Editor: Dr. Natarajan Gajendran

Citation: Shamalti OAQ (2020) The level of practicing feedback patterns by students of field education majoring in Sharia and primary education at King Khalid University. Indian Journal of Science and Technology 13(33): 3484-3494. https ://doi.org/10.17485/IJST/V13i33.1261

*Corresponding author.

qshamalti@gmail.com

Funding: None

Competing Interests: None

Copyright: (c) 2020 Shamalti. This is an open access article distributed under the terms of the Creative Commons Attribution License, which permits unrestricted use, distribution, and reproduction in any medium, provided the original author and source are credited.

Published By Indian Society for Education and Environment (iSee)

ISSN

Print: 0974-6846

Electronic: 0974-5645

\section{The level of practicing feedback patterns by students of field education majoring in Sharia and primary education at King Khalid University}

\author{
Omar Abdel Qader Shamalti ${ }^{1 *}$ \\ 1 Assistant Professor, King Khalid University, Saudi Arabia
}

\begin{abstract}
Objectives: This study aimed at identifying the level of practicing feedback patterns by students of field education who specialize in Sharia and primary education at King Khalid University. Methods/statistical analysis: The study used the descriptive approach based on the study of reality. The sample consisted of (30) students enrolled in field education course, who specialize in Sharia and primary education at King Khalid University. The study instrument was a questionnaire consisting of (25) items that were applied to the study sample. After receiving the returned questionnaires, data were analyzed using the appropriate statistical methods. Findings: The results of the study showed that the level of practicing feedback patterns by students of field education, who specialize in Sharia and primary education was high. The results also showed that there were no statistically significant differences between the mean scores of the level of practicing feedback patterns by the sample of the study due to specialization. Applications/Improvements: In light of the results, the study presented a number of recommendations and proposals.
\end{abstract}

Keywords: Practice; field education students; feedback patterns

\section{Introduction}

The university stage is a very important phase in students' lives because it prepares them to engage in future life and to become active members in their communities. Student acquire the necessary skills and competencies that qualify them to find opportunities in the marketplace. The effectiveness of university teaching is not demonstrated without being examined and evaluating students' performance. The evaluation process is an urgent necessity to achieve the continuous development of both the university student, the faculty member and the curriculum, and all other means that are used to achieve the university's goals and mission ${ }^{(1)}$.

The educational process is affected by a number of factors, including the teacher's practices and styles, such as the chosen teaching methods to achieve the teaching objectives, raising the motivation of learners, and the use of feedback methods in a manner that ensures the provision of an appropriate class environment. This can only 
be achieved through the use of feedback methods that enhance learners' performance and direct their responses in a way that make them feel achieving their comprehensive and integrated growth ${ }^{(2)}$.

\section{Literature Review}

Feedback is one of the modern educational concepts that emerged in the second half of the twentieth century, with issues raised by Nobert Weiner. He first studied the applied sciences and engineering sciences, which are concerned with the so-called discipline, and then moved to relate feedback to the fields of education and psychology. Because of its importance, feedback patterns received great attention from educators and psychologists to include all knowledge and sciences ${ }^{(2)}$. Al-Bashir et.al ${ }^{(3)}$ believe that feedback is an important issue in the field of education because it is an essential element to improve the learning process. Many research and studies consider feedback to be vital and show its value and effectiveness in the education process.

Many and various definitions of the concept of feedback emerged in psychology, and they differ greatly in their linguistic form, but they are similar in content. The concept of feedback was mentioned in the glossary of educational sciences as "information on the progress of teaching and learning obtained through indicators" ${ }^{(4)}$. Feedback is also defined as receiving information to the brain from the executive organs about the nature of the performance or behavior modification ${ }^{(5)}$. Obaidat and Abu Al-Semaid ${ }^{(6)}$ defined feedback as the reactions that the learner receives regarding his/her behavior. Afifi ${ }^{(7)}$ added that it is what the learners receive from information after responding to the required educational tasks to know the results of their learning performance, whether it is right or wrong, which guides them in the learning process. This indicates that feedback patterns are methods that the teacher implements, such as his/her reactions and comments on student performance during the completion of the educational process or after its completion.

Feedback is based on a number of basic principles mentioned by Sutton ${ }^{(8)}$. Feedback provides high-quality information for students about their learning, facilitates the development of self-evaluation in the educational learning process, encourages dialogue on learning, and helps in clarifying the nature of good performance. It also provides the opportunity to enhance performance, encourages motivation, positivity and self-esteem, and provides information to learners to help in the whole learning process.

\subsection{Importance of Feedback in the Learning Process}

The goal of feedback is to modify behavior to avoid the weaknesses faced by the student and confirm positivity, and to reinforce it. Feedback is one of the basic elements of brain development and enhancement towards intelligence ${ }^{(9)}$. It also provides the student with the conditions during which the work will be carried out. It determines the level of performance and the level of achievement, especially after the student begins performing, he can receive feedback during his work, or after completion.

Feedback builds a safe educational environment based on mutual friendliness between the teacher and the learner while affirming and appreciating the learners. It works to change the learners' perceptions related to their abilities and indicate the level of their progress and educational growth in a consecutive way. Feedback helps to improve and develop the different skills of learners and thus positively affects their academic achievement, and the advancement of their educational level during the feedback period ${ }^{(10)}$. Feedback also inform learners of the outcome of their learning, which reduces the anxiety and stress that they may experience if they do not know these results, and encouraging them to continue the learning process while it is occurring ${ }^{(11)}$. In addition, learning takes place with less effort and in a short time because guidance leads to a shortening of the time and effort needed to learn something.

Practicing feedback stimulates the learners' motivation towards learning. Learners will identify the results of their achievement by spotting weaknesses and strengths. In this sense, learners' increase the sense of happiness associated with the correct performance, as well as the sense of shame to avoid repetition of a specific negative behavior ${ }^{(12)}$. Feedback helps students to improve their writing skills. Writing comprehensive comments on their texts means that the reader's response to what the student writes and producing written text with minimal errors and maximum clarity ${ }^{(13)}$. It is an important process and a means of social interaction between members of society. Its use in the field of education contributes to shaping educational and professional behavior ${ }^{(14)}$. However, feedback can have positive or negative results based on a number of factors that affect the student's self-efficacy, motivation, and emotional construction ${ }^{(15)}$. Feedback has become an important and integral part of the various learning theories and principles, providing the learners with the results of their learning and observing their performance directly, and then correcting their mistakes ${ }^{(16)}$. 


\subsection{Sources of feedback}

The student can receive feedback from multiple sources such as the teacher or his colleagues. Learners may refer to a standard to examine their behavior, such as referencing a book or dictionary to compare their answers with what was mentioned in these references. It may be subjective in the sense that learners contemplate the activity and their behavior and analyzes it, and identify their strengths and weaknesses. Learners also receive feedback from their family at home, who often give them feedback on their behavior. It is useful to have multiple sources of feedback because the individual source may present a special point of view while the views issued by multiple sources are complementary, hence educators find a starting point to practice feedback ${ }^{(6)}$.

\subsection{Conditions of feedback}

In order for the teacher to have the opportunity to use the feedback in the classroom situations, and to achieve the desired goals in the processes of improvement and development intended to be achieved in the educational learning process, the following conditions must be met ${ }^{(14)}$ :

- Feedback should be provided consistently and continuously.

- Feedback should be done in light of specific goals.

- Interpreting and understanding the results of a feedback requires deep understanding and careful analysis.

- The feedback process should be comprehensive, including all elements of the educational process and all learners of all levels, achievement, mental and age levels.

- The necessary tools should be used precisely in the feedback process.

\subsection{Patterns of feedback}

Feedback has multiple patterns and forms. Each of them has characteristics that distinguish it from the other according to different learning situations, as well as according to the purpose for which it was found and can be summarized as follows:

First: According to the source, feedback is divided into two parts:

1. External feedback: It consists of information or references provided by an external source, such as the teacher, trainer, or experimenter, to the student to inform him of the wrong or unnecessary answer that he should avoid. External feedback may be presented in the form of oral or written forms, in the form of a procedure or action, or in the form of apparent emotions and expressions. Perhaps the different evaluation methods are the most important sources of external feedback.

2. Internal Feedback: It is the information that the learner extracts directly from his experiences and practices. Through it, it is inferred how successful or failed he is to perform a specific task or behavior ${ }^{(12)}$.

Second: According to the way the learner receives feedback:

1. Direct (explicit) feedback: It is the information that one of the parties to the communication or educational/learning process provides to the other party (the teacher, the trainer, the expert, the peers) directly and without any mediator about the results of his actions.

2. Indirect (implicit) feedback: It is the information that is provided indirectly and using various media. For example, by submitting messages and reports, or by other people, or through designs and suggestions, or by the media. Some scholars prefer indirect feedback in many learning or working situations, in order to exclude the influence of the situation as a whole. However, the majority of educators prefer direct feedback, especially in classroom teaching and learning, and they see it as more effective than indirect feedback, especially if there are factors of accuracy, diligence, and objectivity on the part of those who provide it ${ }^{(6)}$.

Third: According to the time it is provided: Immediate feedback:

1. This pattern comes after a behavior or a performance directly, and provide the learner with the information, directions, instructions, or suggestions required to reinforce, modify, or correct the work. This pattern is related to the observed behavior, and the student is provided with information about the progress of his performance in the test or activity immediately after the answer. This type is prevalent in individual learning methods. Scientists, headed by Skinner, stressed the importance and vitality of this type of feedback. This is confirmed by "Amons" research on this by saying: The learner's performance decreases and deteriorates if the immediate feedback is obscured or its presentation is delayed for a short 
period ( 15 seconds) after the end of the response. This may be due to the fact that the feedback given in due time as a result of the delay reduces the learner's enthusiasm, makes him frustrated and does not prevent at the same time from committing the mistakes that he had previously made.

2. Deferred feedback: This pattern is given to the learner after a period of time has passed since the completion of the work, or performance. This period may be longer, or shortened according to the circumstances and as the case may be. Examples include:

(a) Waiting until the end of the year to issue results of success or failure.

(b) Neglecting some negative behaviors.

(c) Discussing negative behaviors with the students after a period of time has passed since the occurrence of such behaviors ${ }^{(12,17)}$.

Fourth: According to the method of providing feedback:

1. Verbal feedback: It is linguistic utterances provided to the student and the learner cannot refer to it at all times, and it is subject to forgetfulness.

2. Non-verbal feedback: It happens with guidance and kinesthetic gestures such as head movement or looking at the eyes, which are of great influence in the educational process.

3. Written feedback: It is by writing and the learner can refer to it all the time, such as the notes written on the answer sheet, or written on the subject matter ${ }^{(12)}$.

Fifth: According to feedback function.

1. Informative feedback, which is to give the learner information about the accuracy of the answer.

2. Corrective feedback, through which the learner is provided with information about the accuracy of his answer, while correcting the wrong answers.

3. Explanatory feedback, which includes providing the learner with the necessary information about the correctness of his answer, and correcting it.

4. Reinforcing feedback, which is to give the learner information about the accuracy of his answer, correct wrong answers, and discuss the causes of the error in addition to providing expressive terms ${ }^{(10,14,17)}$.

Sixth: According to effect on the learner.

1. Positive: It means telling the learner that his answer to the question is correct, praising the answer, which increases his confidence in retrieving his experiences in other situations, and this may change his level of motivation.

2. Negative: It indicates the teacher's dissatisfaction with the learner's answer to a specific question without giving any comment or explanation. Negative feedback may lead to more stress to the learner ${ }^{(10,17)}$.

\subsection{Previous research}

Many researchers have been interested in feedback. They used the technique of feedback in their research and studies at all educational levels, starting from the primary stage to the university stage.

Ayasrah and Shabibi ${ }^{(18)}$ conducted a study aimed at identifying the reality of the use of Islamic education teachers in the Sultanate of Oman for immediate corrective feedback in classroom discussions. The study sample consisted of (36) male and female teachers. The Note Card was used in the study and included corrective feedback methods. The study concluded that implicit correction is the most used corrective feedback method in classroom discussions. The results showed statistically significant differences in the use of corrective feedback methods according to the variable of the lesson type in most methods.

(13) conducted a study aimed at analyzing written feedback on ESL student writings. The written feedback was divided into: feedback within the written text, and feedback to the text in general. A model was developed for analysis based on two basic speech roles: guidance and expression. The study sample consisted of (15) students representing different categories. The results of the study indicated that the written feedback provided to the students was useful, and that their attitudes were positive towards its use.

Ashour and Al-Harahsheh ${ }^{(16)}$ investigated the effect of using feedback on improving the listening skill of fifth-graders. The sample of the study consisted of (72) male and female students applying an achievement listening test. The study results showed that there are statistically significant differences in listening skills, all of which are attributed to the effect of feedback. 
Al-Qawas ${ }^{(19)}$ identified the degree of using methods of continuous evaluation and feedback by faculty members at the Faculty of Education, University of Ibb from the viewpoint of their students. The sample of the study consisted of (258) male and female students from the Faculty of Education at Ibb University. The study found that the degree to which faculty members use continuous evaluation and feedback methods was weak.

Brown et al. ${ }^{(20)}$ conducted a study aimed at revealing students' attitudes towards the roles of feedback and the relationship between feedback and self-organized learning, self-efficacy and achievement. Researchers prepared a questionnaire to collect data from a sample of (278) university students. The results showed connections between positive feedback and self-learning. Feedback contributes to self-organization, academic competence, and student grades.

Carver ${ }^{(21)}$ aimed at revealing students' feeling toward feedback in the classroom. The researcher used a large-scale questionnaire distributed to the study sample, as well as semi-structured interviews with a focus on how students understand feedback. The results of the study showed the students 'appreciation of the teachers' feedback. The study showed that there are simple models through thinking that can encourage students to education through feedback.

Mansantiah et al. ${ }^{(2)}$ identified the interaction between the level of students' ability to solve problems and feedback. The study sample consisted of (786) students. The sample was divided into three groups: the excellent group, the moderate group, and the poor group. The results found that the excellent group had the ability to solve problems using feedback more than the moderate and poor groups.

Al-Mutairi ${ }^{(17)}$ conducted a study to reveal the impact of the difference in the feedback pattern (teacher evaluation/peer evaluation) in electronic blogs on the development of academic achievement of high school students on the computer curriculum and information technology in Dawadmi Governorate. The study sample consisted of (30) students. The study used the quasi-experimental approach. The results of the study showed the effectiveness of using electronic blogs to develop academic achievement and the effectiveness of feedback in electronic blogs on developing achievement.

Abdullah ${ }^{(10)}$ identified the level of practice of feedback patterns by kindergarten teachers and the requirements of their success. The sample of the study consisted of (89) female teachers and to collect the data of the researcher developed a note card and conducted interviews. The results concluded that the degree of kindergarten teachers' practice of the feedback patterns was medium.

Tarif et al. ${ }^{(2)}$ conducted a study aimed at revealing the predictive power of both feedback and the teacher's relationship with the student in self-organized learning. The sample of the study consisted of (647) pre-teacher students. The sample responded to a feedback questionnaire, the questionnaire on the teacher's relationship with the student, and the questionnaire on selforganized learning. The results of the study found that the level of student feedback was an average score for the tool as a whole. The teacher's level of relationship with the student is average over the instrument as a whole. The same applies to the level of self-organized learning.

\subsection{Problem of the study}

The primary function of contemporary education is to create a sound practical plan that will achieve comprehensive growth for students, helping them to live in a constantly changing society. This could be achieved by providing favorable conditions for learning and education that enable them to reach their full potential. In the core of the learning and teaching processes, feedback emerges as a vital and important element that contributes to achieving effective learning processes. The role that feedback plays in education stems from the principles of behavioral, correlational theories that confirm the fact that an individual changes his behavior when he knows the results of his previous behavior. This theory confirms the role of motivating feedback in motivating students and directing their energy toward learning. It also contributes in strengthening information, and thus contribute to improving the level of their performance of subsequent educational tasks.

Hence, the study problem is to answer following main question:

What is the level of practicing feedback pattern by students of field education who specialize in Sharia and primary education at King Khalid University?

More specifically, the study tries to answer the following questions:

1. What are the feedback patterns to be used by field education students who specialize in Sharia and primary education at King Khalid University?

2. What is the level of practicing feedback patterns by students of field education who specialize in Sharia and primary education at King Khalid University?

3. Are there any statistically significant differences in the level of practicing feedback patterns by students of field education who specialize in Sharia and primary education at King Khalid University attributable to the specialty? 


\subsection{Significance of the study}

The significance of this study stems from the nature of the subject of the patterns of feedback that should be used by field education students who specialize in Sharia and primary education at King Khalid University. Feedback patterns are important pillars of the education process and should be investigated to identify the impact of using such technique. Moreover, the results of the current study may represent a starting point for more general and comprehensive research and studies that will prepare pre-service and in-service training courses for teachers.

\subsection{Objectives of the study}

The study attempts to achieve the following objectives:

- Identifying feedback patterns that should be used by field education students who specialize in Sharia and primary education at King Khalid University.

- Identifying the feedback patterns used by field education students who specialize in Sharia and primary education at King Khalid University during their training.

- Identifying the difference between the responses of the study sample to determine the feedback patterns used by field education students who specialize in Sharia and primary education at King Khalid University due to specialization.

\subsection{Limitations of the study}

The study was conducted in light of the following limitations:

- The study was limited to a sample of field education students specialized in Sharia and primary education at King Khalid University.

- The study was conducted during the first semester of the academic year 2019-2020.

- The results of the study are determined by the method of selecting the study sample, the extent of its representation to the original study population, as well as the extent of assessments of the sample.

\subsection{Definitions of terms}

Practicing feedback patterns: The performance of field education students who specialize in Sharia and primary education in applying feedback patterns during the teaching process. It is related to and track the observed behavior directly, and provide the other party individually with information, guidance, and instructions to enhance, improve, develop, or correct the behavior. These patterns could be written or oral. In this study, it is measured in what was mentioned in the researcher's observation of the sample according to the observation card.

Field education students: Students of the last level from the Faculty of Sharia or the Faculty of Education who have successfully completed all their courses and study the field education course during the first semester of the academic year 2019-2020.

\section{Methodology}

The study followed the descriptive analytical method, which depends on collecting data, tabulating them, analyzing them, then extracting the results. Darwish ${ }^{(23)}$ defines this approach as "a method on which researchers rely to obtain adequate and accurate information depicting reality and contributes to the analysis of its phenomena."

\subsection{Sampling}

Table 1. Distribution of the study sample according to specialization

\begin{tabular}{ll}
\hline Specialization & No. \\
\hline Primary education & 15 \\
Sharia & 15 \\
Total & 30 \\
\hline
\end{tabular}

The study population consisted of field education students who specialize in Sharia and primary education at King Khalid University during the academic year 2019-2020. The sample of the study consisted of (30) students from field education students, 
who were chosen purposefully and study the field education course during the first semester of the academic year 2019-2020 as shown in Table 1.

\subsection{Instrument of the study}

To achieve the objectives of this study, the researcher developed the study instrument as an observation card to collect data. It was prepared according to the following steps:

- Preparing a list of feedback patterns that field education students should use.

- Determining the goal of the list, which is to identify the types of feedback patterns that should be used by field education students and formulating them as measurable operational procedures.

- Identifying the sources for preparing the list through reviewing the theoretical literature and previous studies related to the topic.

- Preparing the list in its initial form, and it included (28) items that represent the feedback patterns.

- Presenting the preliminary list to a group of 8 judges specialized in curricula, teaching methods and educational psychology in order to ensure the integrity of the language and the reliability of the items to the patterns of feedback.

- After taking the opinions of the judges into consideration, the list was converted into an observation card that measures the feedback patterns used by field education students during class visits. The card included (25) items.

- Determining the method of measurement in the observation card. The five-Likert scale was approved to correspond to each paragraph included in the observation card. The levels of measurement were very high, high, medium, low, and very low. These alternatives have been granted the following grades: $(5-4-3-2-1)$, respectively. The following table shows the degrees of weight value and the degree of practice of the feedback patterns.

Table 2. Weight value and the level of practicing feedback patterns by students of field education students who specialize in Sharia and primary education according to the five- Likert scale

\begin{tabular}{lll}
\hline Category & Category boundaries & Level of practice \\
\hline 1 & $0-1.8$ & Very low \\
2 & $1.81-2.60$ & Low \\
3 & $2.61-3.40$ & Medium \\
4 & $3.41-4.20$ & High \\
\hline
\end{tabular}

\subsubsection{Validity}

The validity of the observation card was confirmed by the following two methods:

1. Construct validity: To ensure the validity of the observation card and its suitability, it was presented to a group of judges who specialize in curricula and teaching methods at the Faculty of Education at King Khalid University in Abha. The judges indicated that some modifications were made to the way paragraphs were drafted by deletion and addition, and after making the required amendments the judges indicated the validity of the instrument for application to the study sample.

2. Internal consistency: After verifying the construct validity of the observation card, the researcher applied the tool to an exploratory sample of 3 students outside the study sample. The Pearson correlation coefficient was calculated between the score of each paragraph and the total score of the card. The value of the Pearson correlation coefficient between all the paragraphs and the total score of the card was (0.84225), which was positive and statistically significant at (0.01), which indicates the internal consistency of the paragraphs of the card.

\subsubsection{Reliability}

The reliability of the instrument was verified by the way of stability across individuals, where the researcher used the observation of the respondents who participated in the exploratory sample (No. 3). To determine the stability factor, the Cooper equation was used, which states:

$$
\text { Stability Coefficient }=\frac{\text { the number of times of agreement between the first and second observer } x 100 \%}{\text { The number of times of agreement }+ \text { the number of times of disagreement }}
$$

The value of the stability coefficients was (91.34), which is an appropriate stability value, suitable for study purposes. 


\subsection{Procedures}

The study was carried out according to the following procedures and steps:

- Reviewing the literature and previous studies related to feedback patterns.

- Preparing a list of feedback patterns that field education students should use.

- Presenting the list to a group of specialized judges to take their views and make adjustments accordingly.

- Choosing the study sample purposefully from students who are supervised by the researcher in the field.

- Determining the application time of the study, which is the first semester of the academic year 2019/2020.

- Application of the instrument to the exploratory sample, which is outside the study sample, to determine the validity of internal consistency and reliability.

- Applying the study instrument to the study sample and collecting and unloading data via statistical packages (SPSS) to reach the results of the study for discussion and come up with appropriate recommendations.

\section{Results and Discussion}

First: Results related to the first question.

What are the feedback patterns to be used by field education students who specialize in Sharia and primary education at King Khalid University?

To answer this question, a list of feedback patterns that should be used by field education students specializing in Sharia and primary education at King Khalid University was prepared. The list went through a set of steps and procedures previously mentioned that resulted in (25) paragraphs as shown in the Table 3.

Table 3. The list of feedback patterns that field education students who specialize in Sharia and primary education at King Khalid University

\begin{tabular}{|c|c|c|c|}
\hline No. & Paragraph & No. & Paragraph \\
\hline 1 & $\begin{array}{l}\text { Providing learners with their results in the tests } \\
\text { immediately after completing the correction }\end{array}$ & 14 & $\begin{array}{l}\text { Ensuring that the distinguished works of the learners } \\
\text { are presented and published at the school level }\end{array}$ \\
\hline 2 & $\begin{array}{l}\text { Ensuring the enhancement of learners' performance } \\
\text { orally }\end{array}$ & 15 & $\begin{array}{l}\text { Avoiding uncontrolled feelings when a student is } \\
\text { offended }\end{array}$ \\
\hline 3 & $\begin{array}{l}\text { Providing learners with multiple resources that they } \\
\text { can refer to }\end{array}$ & 16 & $\begin{array}{l}\text { Using visual gestures to express satisfaction or dissat- } \\
\text { isfaction with a specific answer }\end{array}$ \\
\hline 4 & $\begin{array}{l}\text { Linking the educational situation to the interests of } \\
\text { learners }\end{array}$ & 17 & $\begin{array}{l}\text { Providing learners with the rules and regulations of the } \\
\text { school }\end{array}$ \\
\hline 5 & $\begin{array}{l}\text { Using verbal auditory reinforcement to express satis- } \\
\text { faction about a specific behavior }\end{array}$ & 18 & $\begin{array}{l}\text { Using modern teaching methods to help learners } \\
\text { develop creative and critical thinking }\end{array}$ \\
\hline 6 & $\begin{array}{l}\text { Urging learners to take responsibility for studying } \\
\text { and obtaining knowledge }\end{array}$ & 19 & $\begin{array}{l}\text { Giving learners multiple opportunities to try to } \\
\text { straighten their performance before providing them } \\
\text { with the correct performance }\end{array}$ \\
\hline 7 & $\begin{array}{l}\text { Planning and working to discover some special } \\
\text { talents and develop them }\end{array}$ & 20 & $\begin{array}{l}\text { Providing an opportunity for learners to correct the } \\
\text { mistakes of their classmates }\end{array}$ \\
\hline 8 & $\begin{array}{l}\text { Identifying common weaknesses and design reme- } \\
\text { dial activities }\end{array}$ & 21 & $\begin{array}{l}\text { Informing the learners of their goals and what they did } \\
\text { not achieve }\end{array}$ \\
\hline 9 & Urging learners to use technology & 22 & $\begin{array}{l}\text { Praising the learners for their calm and positive } \\
\text { interaction after completing the assignments. }\end{array}$ \\
\hline 10 & $\begin{array}{l}\text { Using written reinforcement to express satisfaction } \\
\text { with a specific behavior }\end{array}$ & 23 & $\begin{array}{l}\text { Explaining the reasons for the learner that made his } \\
\text { performance right or incorrect }\end{array}$ \\
\hline 11 & $\begin{array}{l}\text { Informing learners of the importance of performing } \\
\text { what they are assigned to and the benefit that comes } \\
\text { to them of their mastery }\end{array}$ & 24 & Discussing the learners' answers upon completion \\
\hline 12 & $\begin{array}{l}\text { Teachers discuss how to motivate learners and } \\
\text { increase their positive interaction. }\end{array}$ & 25 & $\begin{array}{l}\text { Specifying a monthly class for learners to review the } \\
\text { course }\end{array}$ \\
\hline 13 & $\begin{array}{l}\text { Informing the learners of the importance of sharing } \\
\text { between themselves. }\end{array}$ & & \\
\hline
\end{tabular}


Second: Results related to answering the second question.

What is the level of practicing feedback patterns by students of field education who specialize in Sharia and primary education at King Khalid University?

To answer this question, frequencies and mean scores of responses of field education students were calculated as shown in Table 4.

Table 4. Frequencies, meanscores, and standard deviations of the instrument's paragraphs on the level ofpracticing feedback patterns by students of field education specializing in Sharia and primary education at King Khalid University

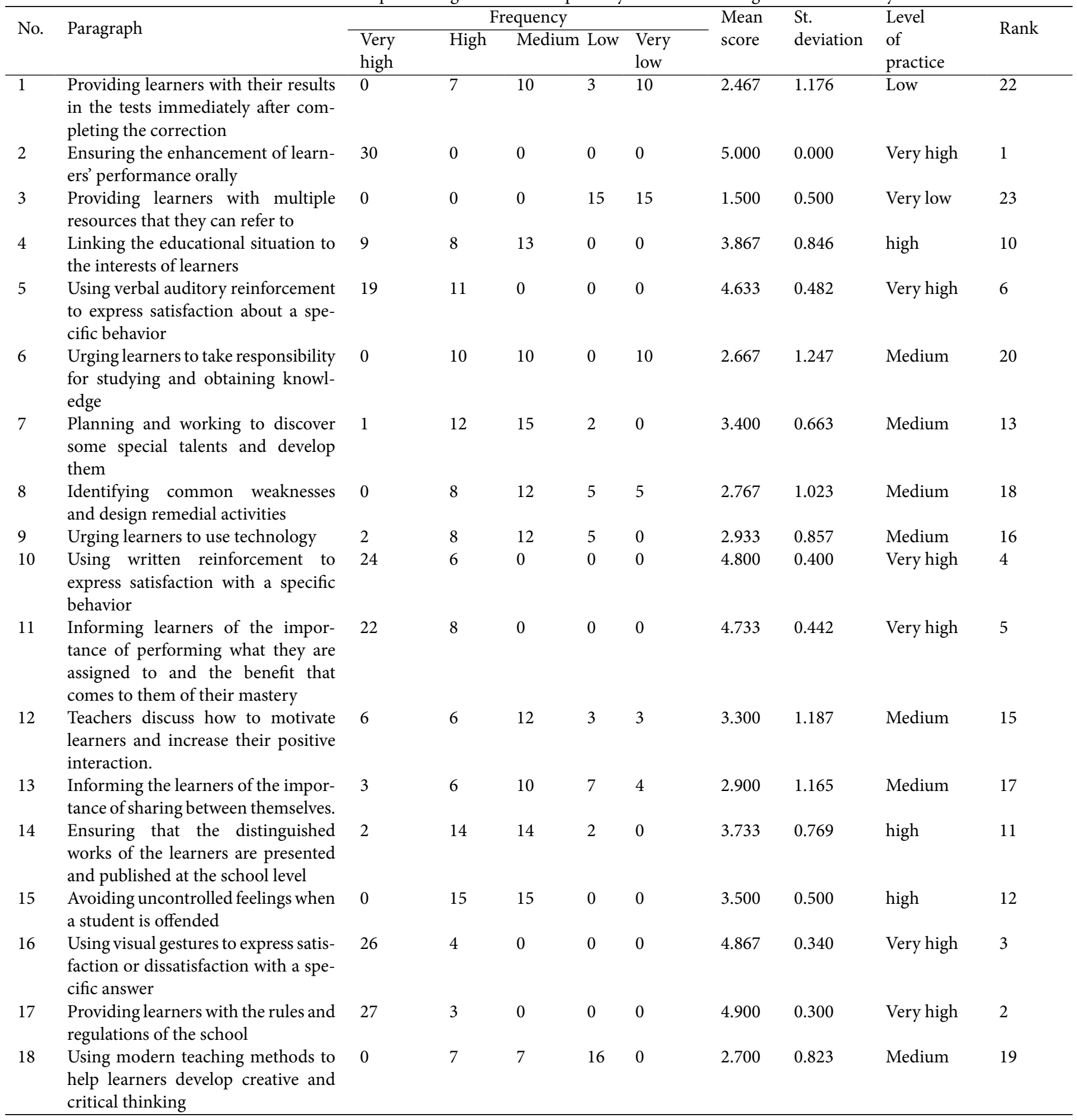




\begin{tabular}{llllllll}
\hline Table 4 continued & & & & & \\
\hline $19 \quad \begin{array}{l}\text { Giving learners multiple opportuni- } \\
\text { ties to try to straighten their perfor- } \\
\text { mance before providing them with } \\
\text { the correct performance }\end{array}$ \\
$\begin{array}{l}\text { Providing an opportunity for learn- } \\
\text { ers to correct the mistakes of their } \\
\text { classmates }\end{array}$ \\
$\begin{array}{l}\text { Informing the learners of their goals } \\
\text { and what they did not achieve }\end{array}$
\end{tabular}

Table 4 shows that the level of practicing feedback patterns by students of field education specializing in Sharia and primary education was high degree. The mean score of the study sample on all areas of the observation card as a whole was (3.656) out of (5) degrees, with a standard deviation of (0.676).

It is also clear from the table that the highest practice of feedback patterns was (Ensuring the enhancement of learners' performance orally), followed by (Specifying a monthly class for learners to review the course), where the mean scores of the two paragraphs reached $(5,000)$ and with a standard deviation of $(0,000)$. This indicates the keenness of supervisors on students of field education to the importance of paying attention to feedback and setting a monthly class for reviewing the course and the commitment of the trainees. The least practice of the feedback patterns was represented in the paragraph (providing learners with multiple sources they can refer to). This may be due to the lack of experience of the trainee students with the necessary references for the course as well as their keenness to finish the official course without the commitment of learners to references and other learning resources.

Third: results related to the third question.

Are there any statistically significant differences in the level of practicing feedback patterns by students of field education who specialize in Sharia and primary education at King Khalid University attributable to the specialty?

To answer this question, the sum of the grades and their means were extracted. The Mann-Whitney test was used for two independent groups as shown in Table 5.

Table 5. Mann-Whitney test for the significance of the differences between the researcher's estimates of the level of practicing feedback patterns by students of field education as attributed to specialization

\begin{tabular}{llllll}
\hline Specialization & No. & Sum of ranks & U-value & Z-value & Sig. \\
\hline Sharia & 15 & 202.00 & 13.47 & \multirow{2}{*}{1.267} & 0.205 \\
Primary education & 15 & 263.00 & 17.53 & & \\
\hline
\end{tabular}

Table 5 shows that there are no statistically significant differences between the mean scores of the researcher's estimates of the level of practicing feedback patterns by students of field education specializing in Sharia and primary education at King Khalid University attributed to specialization. The Z-value in Mann- Whitney test was (1.267), which is not statistically significant at the level of (0.205). This result may be attributed to the great similarity in the educational study plan for both Sharia and primary education specializations. The student of Sharia studies many educational courses before engaging in field education, as is the case for the primary education student.

\section{Conclusion and Recommendations}

This study aimed at identifying the level of practicing feedback by students of field education specializing in Sharia and primary education at King Khalid University. The findings show that the level of using feedback patterns was high, which is a positive 
outcome. Students are enrolled in different courses that prepare them to be aware of the importance of feedback before they start their final application in the field education course. The findings did not show differences in levels due to the difference in specialization, which might be due the many common courses between the two specializations.

In light of the results, the study recommends the following:

- Explaining the importance of feedback in university study.

- Holding training courses for faculty members in universities, and focusing on new members with little experience.

- Urging authors to write separate books on feedback because of its great importance in the teaching process at all educational levels.

\section{Acknowledgments}

The author expresses gratitude to King Khalid University, Saudi Arabia for providing administrative and technical support.

\section{References}

1) Ibrahim $\mathrm{H}, \mathrm{Ahmad} \mathrm{AK}$. The impact of using modern technology in the electronic tests and evaluation of the student as one of the means of developing the quality of university education in the Kingdom of Saudi Arabia. In: and others, editor. The sixth annual conference (patterns of education and quality control standards), AROQA, Sultanate of Oman. 2014.

2) Tarif SM, Al-Atoum AY, Al-Momani AA. The predictive ability of both feedback and the teacher's relationship with the student in self-organized learning. IUJ Journal of Education and Psychology Sciences. 2020;28(21):905-929. Available from: https://search.emarefa.net/detail/BIM-948480.

3) Al-Bashir M, Rezaul K, Rahman I. The Value and Effectiveness of Feedback in Improving Students' Learning and Professionalizing Teaching in Higher Education. Journal of Education and Practice. 2016;7(16):38-41.

4) Al-Shariqi S, Obeikan Library, Riyadh. Glossary of Educational Sciences. 2000.

5) Yunus M. Principles of Psychology. 1st ed. Amman. Al-Shorouk Publishing and Distribution. 2004.

6) Obaidat T, and SAAS. Teaching Strategies in the Twenty-first Century, 1st edition, Dar Al-Fikr, Amman. 2007.

7) Afifi MK. The effect of the interaction between providing feedback (immediate and postponed) in the distance-learning environment and the active (reflective) learning style in achieving some of the learning outcomes among Arab Open University students. Learning technology series of studies and research. 2015;25(2):81-166.

8) Sutton P. Towards dialogic feedback. Critical and Reflective Practice in Education. 2009;1(1).

9) Kovalik SJ, Olsen KD. Exceeding Expectations. Dar Al-Kitab Al-Tarbawi for Publishing Translation, Dhahran Schools. 2004.

10) Abdullah $\mathrm{H}$. The level of practicing feedback patterns by kindergarten teachers and requirements for their success. Childhood and Education Journal. 2019;38:225-272.

11) Gjerde KA, Skinner D, Padgett MY. Feedback Effectiveness: Is It What You Say or How Much You Say It? Journal of Higher Education Theory \& Practice. $2018 ; 18(3)$.

12) Iconsen N, Ichalal S. The Importance of Feedback in the Development of the Linguistic Outcome of Fourth Year Students. Bejaia, Algeria. 2016.

13) Leng KT. An analysis of written feedback on ESL students' writing. In: and others, editor. Procedia-Social and Behavioral Sciences;vol. 123. 2014;p. 389-397.

14) Samerrrai MF. The effectiveness of feedback in developing cognitive performance among male and female teachers. Journal of the College of Education. 2019;15(58):517-547.

15) Carless D, Boud D. The development of student feedback literacy: enabling uptake of feedback. Assessment \& Evaluation in Higher Education. 2018;43:1315-1325. Available from: https://dx.doi.org/10.1080/02602938.2018.1463354.

16) Ashour RQ, Al-Harahsheh NA. The effect of using feedback to improve listening skill among fifth-grade primary students in Jordan. Journal of Al-Qass Open University for Research and Studies. 2015;2(37):287-311.

17) Mm AM. The impact of the difference in the feedback pattern (teacher evaluation / peer evaluation) in blogging on the development of academic achievement among high school students of the computer curriculum and information technology in Dawadmi Governorate. Journal of Educational and Psychological Sciences. 2019;12:167-189.

18) Al-Ayasrah MA, Al-Shabibi TS. The reality of the use of Islamic education teachers in the Sultanate of Oman for immediate corrective feedback in classroom discussions. Journal of Educational and Psychological Sciences. 2012;13(1):132-163.

19) Al-Qawas MA. The degree of using methods of continuous evaluation and feedback by faculty members at the faculty of Education, Ibb university, for from the viewpoint of students, Al-Jame. Journal for Psychological Studies and Educational Sciences. 2016;3:44-60.

20) Brown TLG, Peterson RE, Yao SE. Student conceptions of feedback: Impact on self-regulation, self-efficacy, and academic achievement. British Journal of Educational Psychology. 2016;86(4):606-629. Available from: https://dx.doi.org/10.1111/bjep.12126.

21) Carver M. To what extent is feedback in teacher education 'for learning. .

22) Masantiah C, Pasiphol S, Tangdhanakanond K. Student and feedback: Which type of feedback is preferable? Kasetsart Journal of Social Sciences. 2018. Available from: https://dx.doi.org/10.1016/j.kjss.2018.07.020.

23) Darwish MA. Research Methods in Humanities. Egypt, Nation Sciences Foundation for Cultural Investments. 2018. 